\title{
Synthesis of highly dispersed zirconia-supported iron-based catalysts for Fischer-Tropsch synthesis
}

\author{
F.R. van den Berg ${ }^{\text {a }}$, M.W.J. Crajé ${ }^{\mathrm{b}}$, P.J. Kooyman ${ }^{\mathrm{c}}$, \\ A.M. van der Kraan ${ }^{\text {b, }}$, J.W. Geus ${ }^{\text {a }}$ \\ a Department of Inorganic Chemistry, Debije Institute, Utrecht University, P.O. Box 80083, 3508 TB Utrecht, The Netherlands \\ b Interfacultair Reactor Instituut, Delft University of Technology, Mekelweg 15, 2629 JB Delft, The Netherlands \\ ${ }^{\mathrm{c}}$ National Centre for High Resolution Electron Microscopy, Delft University of Technology, \\ Rotterdamseweg 137, 2628 AL Delft, The Netherlands
}

Received 17 December 2001; received in revised form 23 April 2002; accepted 23 April 2002

\begin{abstract}
Zirconia-supported iron-based Fischer-Tropsch catalysts were prepared using incipient wetness impregnation. The choice of the precursor, in this case the chelating ammonium iron(III) citrate, and the applied calcination temperature determine the final distribution of the precursor on the zirconia support. Several techniques reveal that both an unpromoted and a potassium-promoted catalyst can be prepared, of which the iron(III) oxide exhibits a high dispersion and is, moreover, monodisperse.
\end{abstract}

(C) 2002 Elsevier Science B.V. All rights reserved.

Keywords: Fischer-Tropsch catalysts; Iron based; Potassium-promoted; Zirconia-supported; Calcination temperature

\section{Introduction}

Though supported iron catalysts frequently have been proposed for Fischer-Tropsch synthesis, supported cobalt catalysts are presently preferred $[1,2]$ as it is difficult to suppress the growth of carbon nanofibers from iron particles, which are plugging the reactor [3]. However, it has been established that very small metallic iron particles (less than about $5 \mathrm{~nm}$ ) do not grow carbon nanofibers [4]. However, it is difficult to achieve a high degree of reduction of the supported iron oxide precursor without producing a fraction of large metallic iron particles. Even such a small fraction of large metallic iron particles is capable of producing a large amount of

\footnotetext{
* Corresponding author.
}

carbon nanofibers, since the growth of nanofibers proceeds very rapidly [3]. A high dispersion of the iron particles could be maintained by anchoring particles which are (partly) oxidic to the oxidic support material.

The presence of iron oxide as such during the Fischer-Tropsch reaction, however, is not desired, since iron oxide is known to catalyze the watergasshift reaction, the conversion of carbon monoxide with steam into carbon dioxide and hydrogen [5]. Moreover, using an oxidic iron catalyst, a high hydrogento-carbon monoxide ratio leads to a relatively high production of methane, which is very unfavorable. Starting from methane as presently most preferred feedstock it is already difficult to achieve the desired hydrogen-to-carbon monoxide ratio of about 2 without the carbon monoxide shift conversion proceeding. 
A virtually complete reduction of the iron oxide precursor is therefore the objective.

To obtain small metallic iron particles, a low loading of an iron oxide precursor very well dispersed over the surface of the support is required. With the common oxidic supports silica and alumina it is difficult to prevent reaction of the iron(II), which is initially produced during reduction, with the support to iron(II) silicate or iron(II) aluminate. As both iron(II) silicate and iron(II) aluminate are very difficult to reduce [6-11], silica and alumina are not very suitable as support for iron-based Fischer-Tropsch catalysts. Zirconia does not form bulk iron(II) zirconate, although the interaction with iron oxide is sufficient [12-16] to anchor supported metallic iron particles through an intermediate very thin iron oxide layer.

It has been mentioned that alkali metals, especially potassium and cesium, promote the Fischer-Tropsch synthesis $[5,16]$. Therefore, a reaction of the support with the alkali promoters also has to be avoided. As silica and alumina both react with alkali metal oxides and zirconia does not, we selected zirconia as the support for our supported iron catalyst.

The preparation of very small supported metallic iron particles without a significant fraction of larger iron particles is also interesting, because in literature it is mentioned that it may be possible to produce a commercially interesting fraction of light olefins by performing the Fischer-Tropsch reaction at a relatively elevated temperature [17]. With iron catalysts according to the present state of the art, a higher temperature leads to growth of carbon nanofibers. The ability to selectively and continuously produce a significant fraction of olefins therefore depends on the possibility to prepare catalysts containing metallic iron particles of a size not larger than about $5 \mathrm{~nm}$ without a marked fraction of larger iron particles.

In this, study we have selected a preparation procedure that can be readily scaled up, viz. incipient wetness impregnation, drying and subsequent calcination. After loading in the reactor reduction to metallic iron using hydrogen is performed. Whereas pore-volume impregnation smoothly leads to a homogeneous distribution of the impregnating solution throughout the pores of the support, it is very difficult to maintain a uniform distribution of the precursor during drying. Elsewhere several aspects of the drying step have been described in detail $[18,19]$. Since, the evaporation of the water of the impregnating solution proceeds almost exclusively at the external edge of the support bodies, the liquid migrates to the external edge of the support bodies in the later stages of the drying process as a liquid film on the pore walls of the support. With the usually well soluble salts dissolved in the impregnating liquid, crystallization proceeds at or near the external edge of the support bodies.

Important parameters during the drying step are the change in viscosity of the impregnated liquid during drying, the interaction of the drying solution with the surface of the support and the tendency of the precursor to crystallize within the solution, which becomes more concentrated during drying. van den Brink et al. [18] investigated impregnation and drying of solutions of a considerable number of different iron compounds. This author showed unambiguously that a uniform distribution of an iron oxide precursor and very small iron oxide particles could be achieved by impregnating with a solution of a compound with a chelating anion, such as, ammonium iron(III) citrate. Terörde [20] discovered that the reason for this is that the viscosity of ammonium iron(III) citrate solution increases during evaporation of the water in contrast to solutions of, e.g. iron(III) nitrate.

While van den Brink et al. [18] and Terörde [20] mainly investigated silica supports, Chen et al. [15] employed zirconia supports. These authors prepared their catalyst by impregnation with a solution of iron(III) nitrate. Using Mössbauer spectroscopy (MAS) and X-ray diffraction (XRD) they concluded that the particle size distribution of the iron oxide phase was bimodal containing particles larger than $12 \mathrm{~nm}$ next to smaller particles. Since, the nitrate precursor is highly soluble and not immobilized during drying (no increase in viscosity during drying), the presence of such relatively large iron oxide particles is not surprising. As mentioned above, a better dispersion can be obtained when an organic chelating precursor is employed. Boot et al. $[12,21]$ studied potassium-promoted and unpromoted zirconia-supported iron oxide catalysts using ammonium iron(III) citrate as a precursor. With both the promoted and the unpromoted catalysts he obtained uniform distributions throughout the zirconia support bodies of small iron oxide particles. Investigation of the catalysts on a microscopic scale, however, showed a bimodal size distribution of iron oxide particles. 
MAS indicated the presence of some relatively large particles, the size of which even exceeded $12 \mathrm{~nm}$.

As dealt with above very favorable properties in the Fischer-Tropsch synthesis can be expected from highly dispersed, zirconia-supported metallic iron catalysts. Furthermore, the production of a significant fraction of light olefins may be possible employing suitable iron catalysts in the Fischer-Tropsch synthesis. We, therefore, set out an investigation of the production of zirconia-supported iron catalysts with very small particle sizes using the ammonium iron(III) citrate impregnation method. This paper involves the first step in the synthesis of the catalyst, viz. impregnation and drying of pre-shaped zirconia extrudates with a solution of ammonium iron(III) citrate. The iron oxide particles resulting after calcination are investigated by MAS, XRD, transmission electron microscopy (TEM), and thermogravimetry (TGA).

\section{Experimental}

\subsection{Catalyst preparation}

The catalysts were prepared by means of incipient wetness impregnation. The pre-shaped support material used was zirconia (Norton XZ16075). The zirconia extrudates possessed a pore-volume of $0.28 \mathrm{ml} / \mathrm{g}$ and a specific surface area of $49 \mathrm{~m}^{2} / \mathrm{g}$. Ammonium iron(III) citrate (Merck, 28\% Fe) was employed as precursor to obtain a calculated iron loading of $2.5 \mathrm{wt} . \%$. The potassium-promoted catalyst was prepared by co-impregnation of ammonium iron(III) citrate and potassium carbonate; an atomic ratio $\mathrm{Fe} / \mathrm{K}$ of 1 was applied. For Mössbauer measurements, a citrate complex enriched with the ${ }^{57} \mathrm{Fe}$ isotope was prepared in order to shorten the measuring times. After impregnation, the loaded support was dried at $350 \mathrm{~K}$ in flowing air, and subsequently calcined at $723 \mathrm{~K}$ for $2 \mathrm{~h}$ (heating rates were $5 \mathrm{~K} / \mathrm{min}$ ). These calcined catalysts are referred to as freshly prepared catalysts.

\subsection{Catalyst characterization}

The catalysts are characterized by XRD, TEM, MAS and TGA.

Powder XRD measurements were performed on an Enraf Nonius PDS120 X-ray powder diffractometry system. Co $\mathrm{K} \alpha_{1,2}$ radiation with a wavelength of $1.78897 \AA$ was used. The samples were crushed very finely prior to the measurements.

TEM was performed using a Philips CM30T elec-

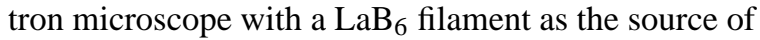
electrons operated at $300 \mathrm{kV}$. Samples were mounted on a microgrid carbon polymer supported on a copper grid by placing a few droplets of a suspension of ground sample in ethanol on the grid, followed by drying at ambient conditions.

Mössbauer absorption measurements were carried out in a constant acceleration mode using a ${ }^{57} \mathrm{Co}$ in $\mathrm{Rh}$ source. Isomer shifts (I.S.) are reported relative to the NBS standard sodium nitroprusside $\left(\mathrm{Na}_{2} \mathrm{Fe}(\mathrm{CN})_{5} \mathrm{NO} \cdot 2 \mathrm{H}_{2} \mathrm{O}\right)$. Magnetic hyperfine fields were calibrated with the $515 \mathrm{kOe}$ field of $\alpha-\mathrm{Fe}_{2} \mathrm{O}_{3}$ at room temperature. The Mössbauer parameters were determined by fitting the spectra with subspectra consisting of Lorentzian-shaped lines using a non-linear iterative minimization routine. The accuracy for the I.S. is $\pm 0.03 \mathrm{~mm} / \mathrm{s}$, for the electric quadrupole splitting (Q.S.) $\pm 0.05 \mathrm{~mm} / \mathrm{s}$ and for the spectral contribution (S.C.) $5 \%$.

The measurements were performed at ambient pressure using an in situ Mössbauer reactor described in more detail in [22]. The freshly prepared unpromoted and potassium-promoted catalysts were measured at various temperatures, viz. 4.2, 77 and $300 \mathrm{~K}$.

A Perkin-Elmer thermobalance was used to assess the amount of carbon that was left on the catalyst from the citrate precursor after the calcination. Therefore, samples of the $\mathrm{Fe} / \mathrm{ZrO}_{2}$ and the $\mathrm{Fe} / \mathrm{K} / \mathrm{ZrO}_{2}$ catalyst were heated in the thermobalance from room temperature to $1123 \mathrm{~K}$. A flow of carefully dried air was passed through the thermobalance. The gas flow out of the thermobalance was analyzed with a mass-spectrometer (Fisons).

\section{Results}

\subsection{Thermogravimetry}

During heating the weight of the ambient air exposed calcined $\mathrm{Fe} / \mathrm{ZrO}_{2}$ catalyst dropped. Up to a temperature of about $473 \mathrm{~K}$ the weight loss was $1.13 \%$ due to the release of water as follows from the mass-spectrometer. At higher temperatures the weight 
decreased due to the reaction of carbon to carbon dioxide. The rate of weight loss due to the combustion of carbon was at a maximum at about $673 \mathrm{~K}$, and the mass-spectrometer displayed a maximum signal of mass 44 due to carbon dioxide. The total weight loss from 473 to $1123 \mathrm{~K}$ was $0.64 \%$, which corresponds to the carbon content of the catalyst. With the loading of $2.5 \mathrm{wt}$.\% iron the atomic ratio of iron and carbon of the freshly calcined $\mathrm{Fe} / \mathrm{ZrO}_{2}$ catalyst is $\mathrm{Fe} / \mathrm{C}=4.5 / 5.3$.

The ambient air exposed calcined $\mathrm{Fe} / \mathrm{K} / \mathrm{ZrO}{ }_{2}$ catalyst lost $0.98 \%$ of its weight due to release of water during heating to a temperature of $473 \mathrm{~K}$. At more elevated temperatures the mass-spectrometer indicated the evolution of carbon dioxide (mass 44). The maximum rate of release of carbon dioxide was exhibited at about $573 \mathrm{~K}$. The weight loss of the $\mathrm{Fe} / \mathrm{K} / \mathrm{ZrO}_{2}$ catalyst due to the combustion of carbon was significantly higher than that of the $\mathrm{Fe} / \mathrm{ZrO}_{2}$ catalyst, viz. $2.09 \%$. The atomic ratio $\mathrm{Fe} / \mathrm{C}$ of this catalyst is 4.5/17.4.

Clearly, both oxidic catalyst precursors still contained a lot of carbonaceous species after the calcination treatment. The carbon content of the potassiumpromoted catalyst turned out to be three times higher than that of the unpromoted one.

\subsection{Transmission electron microscopy and $\mathrm{X}$-ray diffraction of $\mathrm{Fe} / \mathrm{ZrO} \mathrm{O}_{2}$}

For comparison both pure and loaded (but unpromoted) zirconia were investigated. The pure $\mathrm{ZrO}_{2}$ is

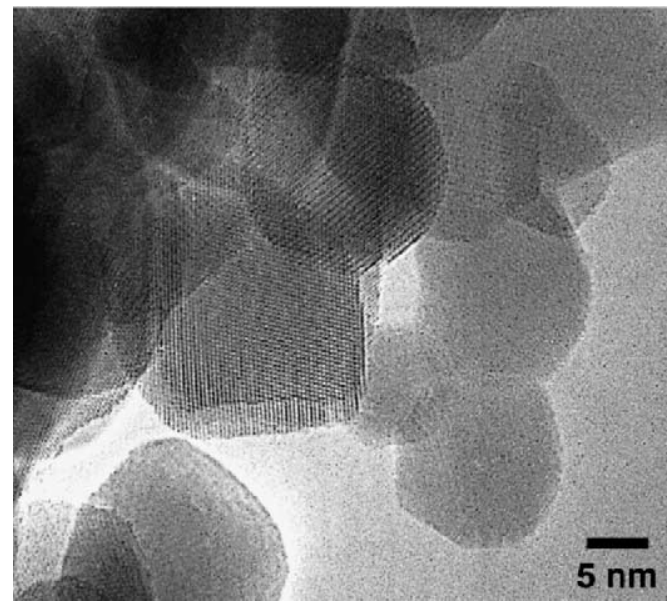

Fig. 1. TEM image of pure $\mathrm{ZrO}_{2}$.

very crystalline as is demonstrated by the long-range ordering of the lattices (Fig. 1 clearly shows fringes indicating the atomic layers). Note that all $\mathrm{ZrO}_{2}$ particles exhibit smooth surfaces.

The XRD profile of the prepared $\mathrm{Fe} / \mathrm{ZrO}_{2}$ catalyst after impregnation and drying at $350 \mathrm{~K}$-as presented in Fig. 2-shows only the ordering of the zirconia which turns out to be purely monoclinic [23]. The XRD pattern of the loaded support after calcination also shows no sign of a long-range ordered iron oxide. The iron oxide species is therefore present as either small (beyond the detection limit, which is approximately $3 \mathrm{~nm}$ ) particles or it is amorphous.

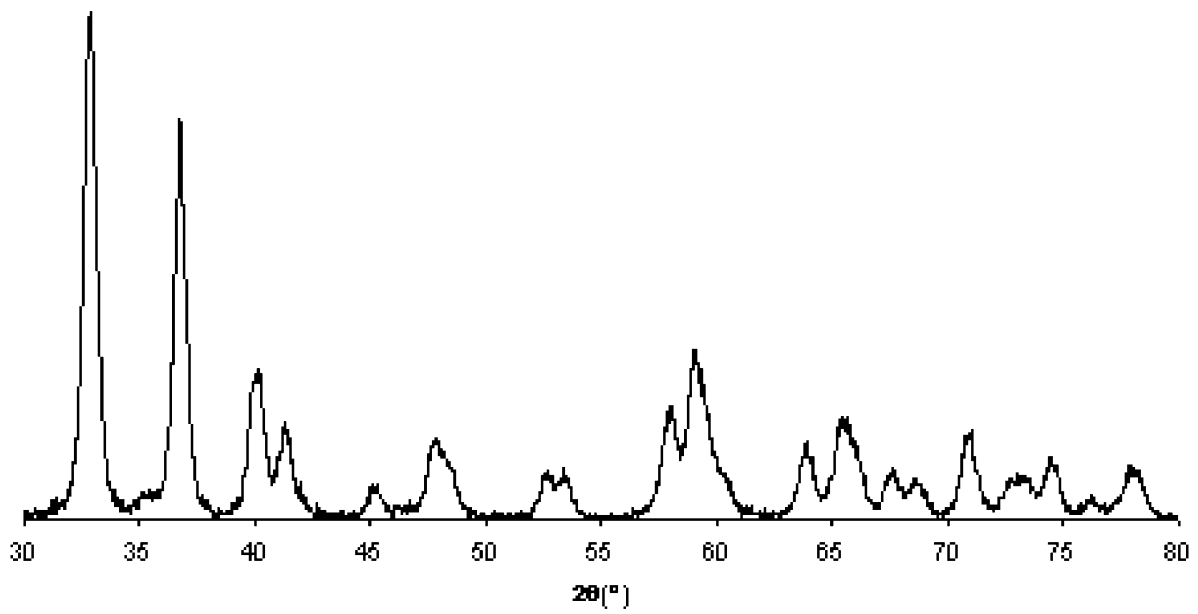

Fig. 2. XRD pattern of the prepared $2.5 \mathrm{wt} . \% \mathrm{Fe} / \mathrm{ZrO}_{2}$ catalyst after impregnation and drying at $350 \mathrm{~K}$. 


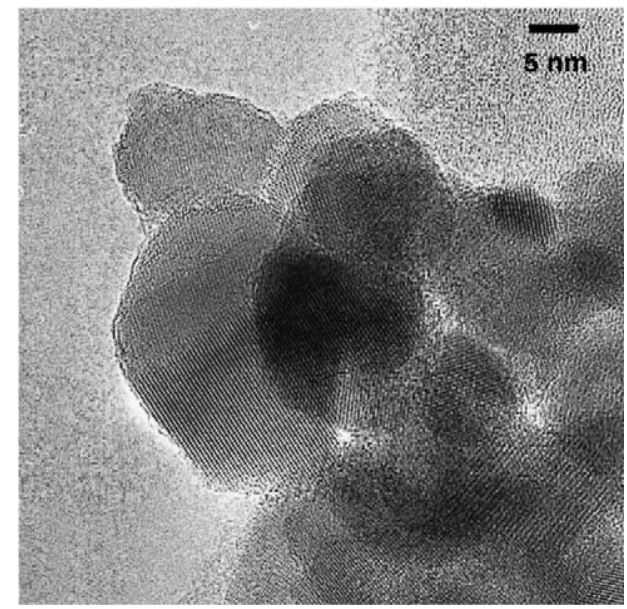

Fig. 3. TEM image of freshly prepared $2.5 \mathrm{wt} . \% \mathrm{Fe} / \mathrm{ZrO}_{2}$ catalyst.

Fig. 3 shows a transmission electron micrograph of the calcined zirconia support loaded with iron oxide. Also in this figure the lattice fringes of the support are clearly visible. The surface of the zirconia crystallites exhibits a very thin amorphous layer of approximately $1 \mathrm{~nm}$ in contrast to the images of the pure support. Energy-dispersive analysis of the emitted X-rays (EDX) shows that the thin layer contains iron. Studying the specimen of the calcined iron-loaded zirconia at a large number of different spots did not reveal the presence of larger crystalline iron oxide particles. The absence of crystalline iron oxide agrees with the XRD results, which do not show any sign of large crystalline iron oxide. It can therefore be concluded that the iron oxide is present in the catalyst within a thin amorphous layer $(1 \mathrm{~nm})$ on the crystallites of the zirconia support.

However, when the iron oxide loading is used to calculate the thickness of the amorphous layer, a different value results. For convenience, the density of crystalline $\alpha-\mathrm{Fe}_{2} \mathrm{O}_{3}\left(\rho=5.24 \mathrm{~g} / \mathrm{cm}^{3}\right)$ was taken for the density of the iron-containing layer. A value of approximately $0.15 \mathrm{~nm}$ results for the thickness of this layer. Even after adjusting for an amorphous iron oxide compound, the experimental thickness cannot be reproduced.

The amorphous layer being thicker than can be accounted for by the iron oxide loading may be due to an inhomogeneous distribution of the iron oxide over the extrudates of the zirconia support or to the iron oxide layer incompletely covering the zirconia crystallites.
An inhomogeneous distribution of the iron oxide over the zirconia can be ruled out. Investigation of randomly taken samples at low magnification in either the light microscope or the scanning electron microscope did not reveal any inhomogeneity. The presence of flat patches of a thickness of about $1 \mathrm{~nm}$ not completely covering the zirconia crystallites of the support is more difficult to exclude based on the images taken in the transmission electron microscope. The amorphous layer is most evident at spots in the specimen where the surface of zirconia crystallites is oriented essentially parallel to the electron beam. Superposition of flat patches of amorphous iron oxide in the image may suggest the presence of a continuous amorphous layer.

However, the amorphous layer being thicker than can be accounted for by the iron oxide loading can be explained by the following. In Section 3.1, it is shown that during the calcination at $723 \mathrm{~K}$ the carbon of the citrate is incompletely removed. The thermal pre-treatment leads to a presumably porous layer of intimately mixed iron oxide and carbon of a uniform thickness on the zirconia support. The carbon remaining after the thermal pre-treatment effectively prevents formation of crystalline iron oxide particles sufficiently large to show up in XRD patterns or displaying diffraction contrast in transmission electron micrographs.

\subsection{Mössbauer absorption spectroscopy}

The measured Mössbauer spectra of the unpromoted and promoted zirconia-supported iron oxide catalysts reveal only a doublet at $T=300$ and $77 \mathrm{~K}$. As shown in the Figs. 4 and 5, at $T=4.2 \mathrm{~K}$ a very broad S.C. of a magnetically split component is found in addition to the central doublet for both catalyst samples. Due to the applied Doppler velocity scales the mean positions of the absorption lines 1 and 6 of the sextuplets are just present on the border of these figures, and hence, not directly visible.

The Mössbauer parameters derived from the spectra measured at 300,77 and $4.2 \mathrm{~K}$ are presented in Table 1 . For the magnetically split spectral components at $4.2 \mathrm{~K}$ the I.S. values, mean effective hyperfine fields " $H_{\text {eff }}$ " and S.C. are given. The parameters are not significantly different for the unpromoted and promoted catalysts. The doublets as well as the magnetically split spectral components can be assigned 


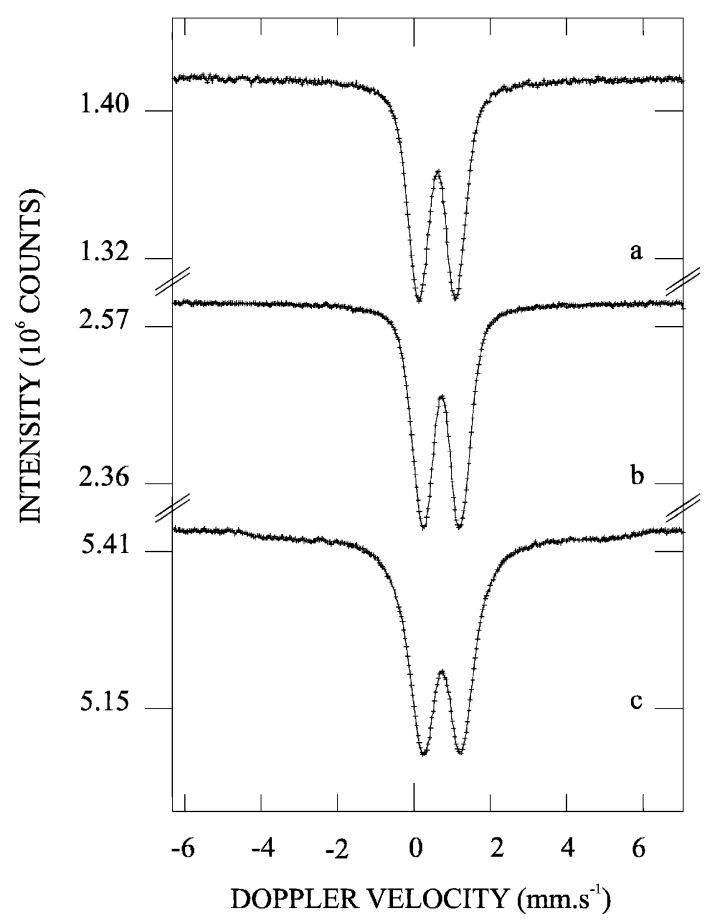

Fig. 4. Mössbauer spectra measured at (a) $300 \mathrm{~K}$; (b) $77 \mathrm{~K}$ and (c) $4.2 \mathrm{~K}$ of freshly prepared $2.5 \mathrm{wt} . \% \mathrm{Fe} / \mathrm{ZrO}_{2}$.

to high spin $\mathrm{Fe}^{3+}$ oxides. The observed line broadening for the doublets and the very broad magnetically split spectral components at $T=4.2 \mathrm{~K}$ point to the presence of a superparamagnetic iron oxide. The dispersion of the iron oxide must be very high (a completely magnetically split spectrum at $T=4.2 \mathrm{~K}$ is observed for particle sizes $\geq 4 \mathrm{~nm}$ of $\mathrm{Fe}_{2} \mathrm{O}_{3}$ [24]).

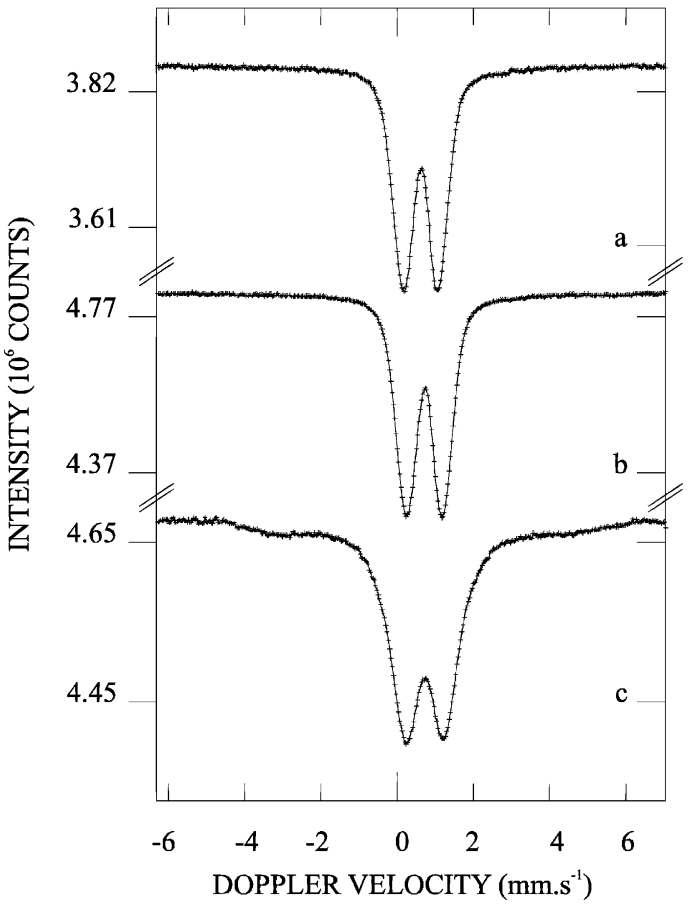

Fig. 5. Mössbauer spectra measured at (a) $300 \mathrm{~K}$; (b) $77 \mathrm{~K}$ and (c) $4.2 \mathrm{~K}$ of freshly prepared $2.5 \mathrm{wt} . \% \mathrm{Fe} / \mathrm{K} / \mathrm{ZrO}_{2}$.

The high dispersion of the iron oxide is supported by the size of the Q.S. Since this splitting depends on the electric field gradient, it is a measure for the asymmetry of the environment of the iron ions. van der Kraan [24] concluded that the Q.S. for iron ions present in the surface of $\alpha-\mathrm{Fe}_{2} \mathrm{O}_{3}$ is higher than for iron ions present in the interior of the oxide, viz. $0.92 \pm 0.04$

Table 1

Mössbauer parameters for fresh $2.5 \mathrm{wt} . \% \mathrm{Fe} / \mathrm{ZrO}_{2}$ and $\mathrm{Fe} / \mathrm{K} / \mathrm{ZrO}_{2}$ at different temperatures

\begin{tabular}{|c|c|c|c|c|c|c|}
\hline$T(\mathrm{~K})$ & I.S. $(\mathrm{mm} / \mathrm{s})$ & Q.S. $(\mathrm{mm} / \mathrm{s})$ & $\Gamma(\mathrm{mm} / \mathrm{s})$ & " $H_{\mathrm{eff}} "(\mathrm{kOe})$ & S.C. $(\%)$ & Compound \\
\hline \multicolumn{7}{|c|}{$\mathrm{Fe} / \mathrm{ZrO}_{2}$} \\
\hline 300 & 0.60 & 0.99 & 0.57 & & 100 & $\mathrm{Fe}^{3+}$ \\
\hline 77 & 0.72 & 1.00 & 0.57 & & 100 & $\mathrm{Fe}^{3+}$ \\
\hline \multirow[t]{2}{*}{4.2} & 0.73 & 1.04 & 0.81 & & 50 & $\mathrm{Fe}^{3+}$ \\
\hline & 0.73 & & & 420 & 50 & $\mathrm{Fe}^{3+}$ \\
\hline \multicolumn{7}{|c|}{$\mathrm{Fe} / \mathrm{K} / \mathrm{ZrO}_{2}$} \\
\hline 300 & 0.61 & 0.93 & 0.57 & & 100 & $\mathrm{Fe}^{3+}$ \\
\hline 77 & 0.71 & 0.97 & 0.57 & & 100 & $\mathrm{Fe}^{3+}$ \\
\hline \multirow[t]{2}{*}{4.2} & 0.72 & 1.05 & 0.91 & & 65 & $\mathrm{Fe}^{3+}$ \\
\hline & 0.73 & & & 420 & 35 & $\mathrm{Fe}^{3+}$ \\
\hline
\end{tabular}


and $0.52 \mathrm{~mm} / \mathrm{s}$, respectively. We observed a value of $0.99 \mathrm{~mm} / \mathrm{s}$, which closely resembles the Q.S. of surface ions. Hence, the iron phase in our catalyst exhibits a large fraction of surface ions.

\section{Discussion}

Using the incipient wetness impregnation technique it turned out to be possible to prepare a zirconia-supported iron oxide catalyst of a high dispersion as is shown with TEM and MAS. The MAS spectra clearly show that all iron(III) oxide particles in both the unpromoted and promoted catalysts are $\leq 4 \mathrm{~nm}$. In the following, our catalyst synthesis is compared to other synthesis routes described in literature. In particular, the applied calcination temperature is discussed.

After the drying step a very thin amorphous layer of the citrate precursor has been deposited on the support. This is due to the high increase in viscosity upon drying which generates a (flat) gel-like structure on the entire surface of the support [20]. To maintain the thin layer containing iron oxide and carbon the temperature during calcination appears to be essential. Boot et al. $[12,21]$ calcined up to a temperature of $1023 \mathrm{~K}$. MAS of this calcined catalyst showed a magnetically splitted spectral component even at room temperature, which unambiguously indicates the presence of iron oxide particles larger than $12 \mathrm{~nm}$. TEM and XRD confirmed the presence of larger iron oxide particles in the catalysts investigated by Boot for both the unpromoted and the potassium-promoted zirconia-supported iron oxides, which had a higher loading with iron oxide.

van den Brink et al. [18] used the impregnation method to deposit ammonium iron(III) citrate on a silica support (OX50, Degussa Germany, specific surface area $50 \mathrm{~m}^{2} / \mathrm{g}$ ). The catalyst was calcined at a significantly lower temperature, viz. $770 \mathrm{~K}$. A sextuplet was revealed only at a temperature of $77 \mathrm{~K}$, indicating the presence of a (small) fraction of particles larger than $4 \mathrm{~nm}$. In the present study, a calcination temperature of $723 \mathrm{~K}$ was used. It is shown that even at temperatures as low as $4.2 \mathrm{~K}$ a magnetically split spectral component is hardly present. This leads to the conclusion that the iron oxide in the presently investigated catalysts is highly disperse and, moreover, monodisperse. The combination of TEM, TGA and MAS has made it clear why a high dispersion is maintained. The carbon remaining after the thermal pre-treatment effectively prevents formation of crystalline iron oxide particles sufficiently large to show up in XRD patterns or displaying diffraction contrast in transmission electron micrographs.

In the following, the possible nature of the potassium species present in the catalyst will be discussed. In view of this, the interaction of potassium carbonate during calcination with the iron oxide and the carbonaceous material resulting from the decomposition of the citrate has to be considered. Potassium carbonate reacts at more elevated temperatures (above $1000 \mathrm{~K}$ ) with iron(III) oxide to potassium ferrite, $\mathrm{KFeO}_{2}$, under release of carbon dioxide $[25,26]$. If the $\mathrm{Fe}_{2} \mathrm{O}_{3}$ species is highly dispersed and also in the presence of steam the reaction to $\mathrm{KFeO}_{2}$ occurs already at $723 \mathrm{~K}$ [27]. $\mathrm{KFeO}_{2}$ has a characteristic light-green color, but the compound is not stable upon exposure to atmospheric air $[28,29]$. The olive green color was never observed in our experiments. Stobbe [28] observed $\mathrm{KFeO}_{2}$ at calcination temperatures above $923 \mathrm{~K}$ for a well-dispersed iron-on-magnesia catalyst. Zirconia-supported iron-based catalysts reveal $\mathrm{KFeO}_{2}$ after calcination at $1023 \mathrm{~K}$ [29]. Both Stobbe [28] and Boot [29] prepared their catalysts through incipient wetness impregnation with the same precursors (ammonium iron(III) citrate and potassium carbonate) as applied here. The main difference between their experiments and those described here is the lower calcination temperature, namely $723 \mathrm{~K}$. Apparently, this temperature is too low for the reaction to $\mathrm{KFeO}_{2}$ to occur and, moreover, Mössbauer experiments have not shown any sign of the potassium ferrite. Although the ferrite is not present, Boot has shown using infrared experiments that $\mathrm{K}_{2} \mathrm{CO}_{3}$ is present after calcination [29]. Based on the aforementioned it is likely that $\mathrm{K}_{2} \mathrm{CO}_{3}$ is initially present in our catalyst.

In literature, it is reported that this carbonate may react with hydrogen to potassium hydroxide $(\mathrm{KOH})$ or it may disproportionate to potassium oxide $\left(\mathrm{K}_{2} \mathrm{O}\right)$ and carbon dioxide [30,31]. On carbon, $\mathrm{KOH}$ and/or $\mathrm{K}_{2} \mathrm{O}$ spread out over the carbon surface [32], impeding the oxidation (of the carbon species) during calcination. Consequently, the carbon content of the catalyst prepared by co-impregnation of potassium carbonate is much higher than that of the catalyst prepared by impregnation of ammonium iron citrate only. 
It appears that the calcination step determines the final microscopic distribution of the $\mathrm{Fe}^{3+}$ species formed. Boot et al. [12] has shown using TEM that large clusters of iron oxide were present in his catalysts after calcination at $1023 \mathrm{~K}$. At this more elevated temperature than applied in the present study $(723 \mathrm{~K})$ the carbon separating the minute iron oxide particles is removed by oxidation. In this manner, contact between the remaining iron oxide particles will be established. Where locally a sufficiently extended contact area between a number of small iron oxide particles arises during calcination, some large iron oxide crystallites result. Therefore, thermally induced migration leading to sintering of the active species is very likely to occur at high temperatures as observed by Boot et al. [12].

\section{Conclusions}

A very thin amorphous layer containing highly disperse iron oxide particles and carbon can be deposited on a zirconia support using the incipient wetness impregnation technique with ammonium iron(III) citrate. TEM, XRD and MAS results reveal the presence of well-dispersed iron(III) oxide (particle sizes, $4 \mathrm{~nm}$ ) in the catalyst precursor $\mathrm{Fe} / \mathrm{ZrO}_{2}$ as well as in the potassium-promoted catalyst precursor $\mathrm{Fe} / \mathrm{K} / \mathrm{ZrO}_{2}$. Although in $\mathrm{Fe} / \mathrm{K} / \mathrm{ZrO}_{2}$ about four times more carbon remains present after calcination $(723 \mathrm{~K})$ no difference in dispersion has been observed between $\mathrm{Fe} / \mathrm{ZrO}_{2}$ and $\mathrm{Fe} / \mathrm{K} / \mathrm{ZrO}{ }_{2}$. A low calcination temperature $(723 \mathrm{~K})$, prevents complete oxidation of the carbon to carbon dioxide and carbon monoxide. In contrast, a higher calcination temperature leads to a more intimate contact between the remaining iron oxide particles and, hence, causes sintering.

\section{References}

[1] S.T. Sie, M.M.G. Senden, H.M.H. van Wechum, Catal. Today 8 (1991) 371.

[2] B. Eisenberg, R.A. Fiato, C.H. Mauldin, G.R. Ray, R.L. Soled, Stud. Surf. Sci. Catal. 119 (1998) 943.

[3] W. Teunissen, Ph.D. thesis, Utrecht University, 2000.

[4] P.H. de Bokx, A.J.H.M. Kock, E. Boellaard, E. Klop, J.W. Geus, J. Catal. 96 (1985) 468.
[5] G.P. van der Laan, A.A.C.M. Beenackers, Catal. Rev. Sci. Eng. 41 (3/4) (1999) 255.

[6] X. Gao, J. Shen, Y. Hsia, Y. Chen, J. Chem. Soc., Faraday Trans. 89 (7) (1993) 1079.

[7] M.V. Cagnoli, S.G. Marchetti, N.G. Gallegos, A.M. Alvarez, R.C. Mercader, A.A. Yeramian, J. Catal. 123 (1989) 21.

[8] A.F.H. Wielers, A.H.J.M. Kock, C.E.C.A. Hop, J.W. Geus, A.M. van der Kraan, J. Catal. 117 (1989) 1.

[9] Y.-Y. Huang, J.R. Anderson, J. Catal. 40 (1975) 143.

[10] M.C. Hobson Jr., H.M. Gager, J. Colloid Interface Sci. 34 (3) (1970) 357.

[11] S. Yuen, Y. Chen, J.E. Kubsh, J.A. Dumesic, N. Topsøe, H. Topsøe, J. Phys. Chem. 86 (1982) 3022.

[12] L.A. Boot, A.J. van Dillen, J.W. Geus, F.R. van Buren, J. Catal. 163 (1996) 186.

[13] E. Guglielminotti, J. Phys. Chem. 98 (1994) 4884.

[14] E. Guglielminotti, J. Phys. Chem. 98 (1994) 9033.

[15] K. Chen, Y. Fan, Z. Hu, Q. Yan, Catal. Lett. 36 (1996) 130.

[16] V. Ponec, in: B. Imelik, et al. (Eds.), Metal Support and Metal-Additive Effects in Catalysis, Elsevier, Amsterdam, 1982, pp. 63.

[17] R. Snel, Catal. Rev. Sci. Eng. 29 (4) (1987) 361.

[18] P.J. van den Brink, A. Scholten, A. van Wageningen, M.D.A. Lamers, A.J. van Dillen, J.W. Geus, Stud. Surf. Sci. Catal. 63 (1991) 527.

[19] L.M. Knijff, Ph.D. thesis, Utrecht University, 1991 (Chapter 2).

[20] R.J.A.M. Terörde, Ph.D. thesis, Utrecht University, 1996 (Chapter 2).

[21] L.A. Boot, A.J. van Dillen, J.W. Geus, A.M. van der Kraan, A.A. van der Horst, F.R. van Buren, Appl. Catal. 147 (1996) 389.

[22] A.M. van der Kraan, J.W. Niemantsverdriet, in: G.J. Long, J.G. Stevens (Eds.), Industrial Applications of the Mössbauer Effect, Plenum Press, New York, 1986, pp. 609.

[23] International Centre for Diffraction Data, JCPDS nr. 37-1484.

[24] A.M. van der Kraan, Phys. Stat. Sol. A 18 (1973) 215.

[25] N.V. Dvoretskii, E.G. Stepanov, T.N. Sudzilovskaya, G.R. Kotel'nikov, V.V. Yun, Kin. Catal. 17 (1976) 654.

[26] J. Subrt, J. Vins, I.S. Shaplygin, A.A. Zakharov, Thermochim. Acta 93 (1985) 489.

[27] L.M. Plyasova, M.M. Andrushkevich, G.R. Kotel'nikov, R.A. Buyanov, G.A. Khramova, S.F. Bednov, Kin. Catal. 17 (1976) 1116.

[28] D.E. Stobbe, Ph.D. thesis, Universiteit Utrecht, 1990 (Chapter 7).

[29] L.A. Boot, Ph.D. thesis, Universiteit Utrecht, 1994 (Chapter 4).

[30] Jan van de Loosdrecht, Ph.D. thesis, Utrecht University, 1995 (Chapter 7).

[31] D.J. Dwyer, Physics and Chemistry of Alkali Metal Adsorption, Elsevier, New York, 1989, pp. 307.

[32] A. Cerfontain, Ph.D. thesis, University of Amsterdam, 1986 (Chapter 3). 